\title{
The development of an organisational effectiveness model
}

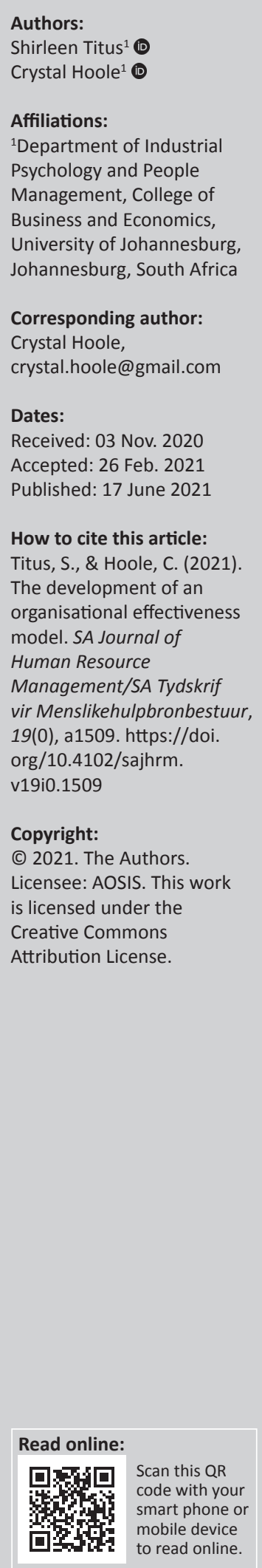

Orientation: Perceived leadership attributes as seen from a multiple stakeholder perspective have an effect on the quality of relationships (social capital) which in return effects organisational effectiveness.

Research purpose: The research aims to build and validate a conceptual model of relationships between perceived leadership attributes (PLAs), social capital (SC) and organisational effectiveness (OE).

Motivation for the study: State-owned companies (SOCs) in South Africa are under enormous pressure and plagued by issues such as mismanagement, poor leadership and poor service delivery. Central to these issues is the relationship between leadership and its stakeholders, and how it affects OE. There is lack of theory about the relationships between the concepts PLAs, SC and OE from a multiple stakeholder perspective.

Research approach/design and method: Adapted grounded theory, using a two-phased exploratory qualitative approach, with purposive sampling was implemented. Phase 1 included collecting data through focus groups and interviews. A Delphi technique was used to validate the model.

Main findings: Multiple stakeholders hold the leadership accountable for demonstrating desirable PLAs such as trust, which builds quality relationships found in SC and factors that lead to OE. Courage, trust and reputation received the highest level of consensus, and several relationships are validated.

Practical/managerial implications: Opportunities exist for the SOCs to strengthen important tangible and intangible attributes, quality relationships and factors that will create a successful turnaround.

Contribution/value-add: This is the first study to investigate the relationship between PLAs, SC and OE in an SOC by multiple stakeholders, culminating in an actionable, validated model.

Keywords: leadership; social capital; organisational effectiveness; leadership attributes; trust; multiple stakeholders; state-owned company; adapted grounded theory.

\section{Introduction}

Leadership earns the right to set the strategic direction (Clarke, Murphy, \& Singer, 2014). Through a process of influencing others, they achieve success, namely, organisational effectiveness (OE) (Martin, 2019; Yukl, 2012).

This implies great accountability to maintain healthy relationships with multiple stakeholders. The quality of the relationships leadership has with stakeholders is an investment found in social capital (SC) (Nohe et al., 2013). Therefore, it is in the interest of leadership to gain an understanding of what stakeholders need from them to obtain co-operation (House et al., 2014; Martin, 2019; Read, 2013).

Leadership refers to the practices of directing a group of people towards the achievement of goals and opportunities (Raelin, 2018; Yukl, 2012). Globally, it has become an obligation for leadership to conduct themselves in a socially, economically and environmentally responsible manner, meeting the needs of current and future stakeholders. Stakeholders are demanding leadership to ensure that both the tangible (financial or hard) and intangible (human related or soft) factors for OE are met (Svenson et al., 2016; Udayaadithya \& Gurtoo, 2014; Warren, 2016; Zadeh et al., 2013). 
Leadership behaviour is embodied by specific desirable and undesirable attributes constantly evaluated and perceived through the eyes of their stakeholders (Lord et al., 2017; Veldsman \& Johnson, 2016). Multiple stakeholders include shareholders, customers, suppliers, employees and the wider community (Robertson et al., 2002).

Given this view, the term 'perceived leadership attributes', abbreviated as PLAs, is introduced. In this study, stakeholders include executives, management, nonmanagement, suppliers and customers who have unique relationships with the state-owned companies (SOCs) and their leadership. Multiple stakeholders need the leadership to be trustworthy and not malevolent (House et al., 2014). The desirable and undesirable PLAs contribute to, or inhibit, the benefits of SC and, consequently, OE (Warren, 2016). Social capital is viewed as an intangible asset that gives an organisation a competitive edge (Buta, 2016). The actual value from SC is found in a quality relationship characterised by trust and collaboration, which leads to OE (Buta, 2016).

Organisational effectiveness therefore goes beyond the financial performance. It includes stakeholder confidence found in the relational dynamics nurtured by leadership (Jiang \& Liu, 2015; Nienaber \& Svenson, 2013). Therefore, understanding the perceptions of multiple stakeholders and acknowledging their inputs increases the possibility of reaching $\mathrm{OE}$.

Key to this study are the concepts PLAs, SC and OE, which are discussed next.

\section{Perceived leadership attributes}

Every theory presented on leadership has its advocates around desirable and undesirable PLAs that lead to OE (House et al., 2014). How well leaders obtain success along with others, is based on the perception of both leadership and stakeholders (Lord et al., 2017). Desirable attributes such as trustworthiness and honesty lead to exceptional leadership, whereas undesirable attributes such as being egocentric and dictatorial lead to ineffective leadership (House et al., 2014).

Important PLAs for effective leadership vary from culture to culture and from stakeholder to stakeholder. Therefore, leadership and stakeholders will differ in their perceptions of attributes (Lord et al., 2017). There are attributes found to be 'most' to 'least' universally desirable, given stakeholder perceptions (House et al., 2014). In the South African context, researchers found that leadership traits such as assertiveness orientation, respect for senior leadership, in-group collectivism, shared responsibility, entrepreneurship, social cohesion and uncertainty avoidance were desirable traits (Geldenhuys \& Veldsman, 2011; House et al., 2014).

Ground-breaking research on the similarities or differences in norms, values and beliefs that lead to unique societal practices reinforces the universal attributes established by Hofstede (1980), Inglehart and Carballo (1997), Schwartz
(1999), Smith et al. (1996) and others (cited in House et al., 2014). Similarly, different meanings to the people, planet and profit attributes are ascribed. For example, caring for people is about compassion, whereas caring for the planet is about social responsibility towards the environment.

Numerous desirable PLAs, such as honesty, integrity and trust, and undesirable attributes such as dishonesty, corrupt behaviours and unethical practices, are considered to be related to the concept of SC (Kwon \& Adler, 2014; Young, 2014). Authors argue that when stakeholders perceive the actions of leadership to be undesirable, there may be a correlation in the decline of collective trust, affecting the quality of the relationships (Jacobson \& Anderson, 2015). This may also hold true in the South African context when tested further.

\section{Social capital}

Social capital has been studied in political, economic, sociological and psychological contexts. Social capital, cited as a tangible and an intangible resource, has value and exists in social and structural systems, interpersonal relationships, networks and values (Fukuyama, 2001; Lins et al., 2017; Read, 2013; Young, 2014). The literature emphasises these attributes can either have a negative or positive impact on organisations and societies in that way (Buta, 2016; Read, 2013).

Amongst stakeholders who benefit from SC are individuals, teams, organisations, communities, suppliers, customers, regulators and government. Leadership is responsible for investing in these relationships, to ultimately build SC, and leverage later in the form of goodwill (Warner, 2012). Given that each stakeholder needs something different from leadership, they will respond to that which serves their own interest and what they value as important. Fundamentally, differences may not always promote co-operation (Buta, 2016). Critics argue that macro-oriented research ignores the fact that individuals do not have equal access to SC and some claim those who live in high SC communities still benefit somehow (Jiang \& Liu, 2015).

At a micro-economic level, cognitive and structural SC, such as individual values, beliefs, attitudes and social norms found in groups, affects the evolution and performance of an organisation (Sargis-Roussel et al., 2017). The attributes are found in the intangible PLAs such as trust and co-operation, which make the organisation more effective (Buta, 2016; Nahapiet \& Goshal, 1998). The sum of organisational SC (relational + cognitive + structural) is impacted by the use of information related to organisational performance, which is an outcome variable (Buta, 2016; Read, 2013).

The presence of SC in organisations is perceived as a consequence of leadership that encourages collective ownership and applies negotiation to resolve the competing interests of stakeholders (Avgar, 2010; Cohen \& Prusak, 2001). Whilst authors hypothesise that there are likely benefits from quality relationships between leadership and stakeholders, clear evidence is not yet available (Read, 2013). 
According to stakeholders, SC is created by desirable PLAs or eroded by undesirable PLAs (Adler \& Kwon, 2002; Fu, Stephenson, \& Ebrahim, 2004). Additionally, SC has a multiplying effect, which results in positive outcomes for all stakeholders (Gholami \& Salimi, 2014). Zavyalova et al. (2016) claimed an organisation often accrues SC earned from goodwill, a high reputation and collective action. In Africa, the value gained from SC inherent in networks and quality relationships in an organisation, cannot be demonstrated (Zoogah et al., 2015). Therefore, a gap exists in the literature.

\section{Organisational effectiveness}

The concept of OE is multidimensional, and leadership realises that $\mathrm{OE}$ extends beyond the traditional predictors for success. Variables such as sustainability, reputation and organisational well-being are relatively complex to define and hard to measure. Few empirical studies have introduced different kinds of $\mathrm{OE}$ models that describe the concept clearly (Mikelsone \& Leila, 2016).

Beyond tangible financial (profit) performance, the principle of the triple bottom line now includes value created from societal (people), environmental (planet), technological (innovation) and cultural (well-being) indicators. The new indicators are deemed critical in monitoring OE (Jacobson \& Anderson, 2015; Mikelsone \& Leila, 2016; Warren, 2016). Organisational effectiveness is fundamentally influenced by the context and timeframe in which the study is conducted.

In 1992, Kaplan and Norton created the balance score card and grouped some of the non-financial measures of $\mathrm{OE}$ (cited in Udayaadithya \& Gurtoo, 2014) into specific categories, namely, customer, learning and growth, and internal business processes. The authors emphasise that the customer measure drives future financial performance. Researchers such as Juvekar and Pandy (2017), Mikelsone and Leila (2016) and Warren (2016) confirmed that financial viability, new technology and societal and environmental changes maintain a competitive edge and must be measured to demonstrate OE.

Organisational effectiveness has been studied in relation to approaches, assumptions, methods, models and perspectives in various contexts (Mikelsone \& Leila, 2016; Nadkarni \& D'Souza, 2015). Leadership develops the business strategy that stimulates performance in others (House et al., 2014). Therefore, the assumption that leadership is the reason for OE is relevant (Hoxha, 2015). When stakeholders work together with leadership taking the lead, the purpose of the organisation can be realised, harnessing people assets (House et al., 2014).

Stakeholders are driven by moral sentiment that explains who they are, what they stand for and how they relate to others (Tantardini \& Kroll, 2015). Achieving OE requires an organisation to reflect on their goals and what they would like to be evaluated on by internal and external stakeholders
(Harter, 2015; Sohmen, 2015). The impact of differences means attributes emerging are different, and often classified as integrated or fragmented. According to Stoughton and Ludema (2012), new insights and development in OE empower leadership to establish a culture of sustainability through sustainable initiatives from an organisational, functional and individual level.

To date, most organisations assess their achievement of $\mathrm{OE}$ by looking at:

- financial performance and shareholder return as considered by economists

- human factors and relational dynamics, as considered by strategists

- emerging behavioural factors such as trust or corporate governance, primarily considered by social scientists (Buta, 2016; Clarke et al., 2014; Lawler, 2014; Nienaber \& Svenson, 2013, Warren, 2016).

Through trust, stakeholders are enabled to function and provide the organisation with a competitive edge (Warren, 2016).

Organisational effectiveness challenges have been experienced as a result of organisations not shifting their mindsets for inclusivity of new models available (Warren, 2016). With increased globalisation, traditional OE definitions are falling short. The ambiguity of language caused by misinterpretation increases stakeholder confusion. For instance, one study asserted that organisations are effective when they reach consensus on the set of goals, where others interpret the goal-based model as the ability of employees to achieve goals (Udayaadithya \& Gurtoo, 2014).

Similarly, creating dissonance in stakeholder relationships should be avoided. In a study conducted on African leadership, dissonance was created by overlooking the sociocultural and historical context and only applying psychological models to measure effectiveness. The inconsistency was largely influenced by cultural beliefs, values and attitudes of the African workforce, and not considering the societal transition (Zoogah et al., 2015). Research can help to contextualise these models more clearly, and in turn, help organisations learn how best to achieve OE.

Arguments for the presence of a positive relationship between PLAs and SC and the likelihood of it positively impacting OE, have been made (Gholami \& Salimi, 2014). For example, charisma, a PLA, will elicit improved co-operation and the understanding of shared goals, an SC indicator, leading to improved team performance, an $\mathrm{OE}$ indicator.

Fundamentally, the complexity of concepts is influenced by the environmental, political, economic, technological, cultural and societal drivers. In the South African context, the political system is fuelled with corruption, increased inequality exists in the economic system and the cultural system is diverse, to name just a few factors. The nonfinancial dimensions such as trust found in, for example, 
reputation, are difficult to measure (Habibi et al., 2014b; Zavyalova et al., 2016). The assumption is that a dimension such as trust relies largely on the perceptions of the public. Therefore, in this study, the rigour comes from including the tangibles and intangibles that are perceived as being important by multiple stakeholders.

\section{Study motivation}

Conceptually, the motivation for this study is inspired by the lack of theory about the relationships between PLAs, SC and OE from a multiple stakeholder perspective and more so in an SOC.

Geldenhuys and Veldsman (2011), House et al. (2014) and Svenson et al. (2016) confirmed that an organisation should become attuned to factors deemed satisfactory by all stakeholders to obtain their commitment.

To address this research gap, the main objective of this study is to develop and validate a conceptual model of the relationships between PLAs, SC and OE, from a multiple stakeholder perspective. More specifically, there is no adequate understanding of how these concepts interact with each other, in the context of an SOC. This research took place in the context of a large SOC that employs a diverse internal staff complement and transacts with multiple external stakeholders. Actively seeking their feedback is essential and will raise public confidence, for example, the current negative perception which has led to a poor reputation, shifts to a positive reputation.

\section{Theoretical contribution}

In this study, a conceptual model was developed illustrating the relationships between PLAs, SC and OE from a multiple stakeholder perspective. This study empirically validates the relationship and helps to explain why attributes such as having a good reputation, building trust, collaborating with others and caring equally about stakeholder needs is going to make a significant contribution in SOCs. These relationships are complex, and the findings contribute towards theory building and the scientific body of knowledge.

\section{Practical contribution}

It is critical for leadership in organisations to have access to a practical model that can contribute to the causal success of the organisation. State-owned companies are confronted with significant challenges for long-term sustainability and how to balance complex priorities. They need increased commitment from all stakeholders towards critical key performance areas to help turn the SOC around.

The practical gain for leadership is that going forward; they should be able to exercise discretion when they make decisions and engage with multiple stakeholders. With greater insights into PLAs, SC and OE as viewed by five stakeholder groups, it can help to shift actions, and accountability, and bring a competitive edge.

\section{Methodology}

An exploratory sequential qualitative approach using adapted grounded theory, and applying flexible strategies to answer the research question, was used to execute the study. According to Charmaz (2006), grounded theory permits the researcher to apply flexible strategies to expedite qualitative data collection and analysis. It may become necessary for the researcher to introduce an alternate technique for collecting data, for example, interviews.

The principles of an adapted grounded theory methodology entail a non-prescriptive approach that novice researchers can apply in qualitative research to discover deeper meaning of the phenomena (Bulawa, 2014). Although some researchers such as Glaser and Strauss (1967) propagated that the literature review is conducted after data collection, there is increasing support to conduct the literature review before data collection, as awareness of the current gaps in the literature forms an important part of the research design and thinking about the research problem (Bryant \& Charmaz, 2007; Hussein et al., 2017).

The primary intent was to hear the perception of multiple stakeholders and to validate a model that could be proposed for studying the relationships of desirable and undesirable attributes of PLAs, SC and OE, in the context of the SOC, which is the overall purpose of this study.

To ensure the quality of the research, the principles of credibility, transferability, dependability, confirmability and authenticity were applied by Guba in 1981 (as cited in Treharne \& Riggs, 2014), as can be seen in Appendix 1. The study was executed in two phases. Phase 1 involved collecting data from focus groups and interviews exploring the phenomenon and generating themes to develop the model, which was validated in phase 2 using a Delphi survey.

According to Henning et al. (2010), working with qualitative content analysis as grounded theory analysis, the researcher has options for converting the raw data into final patterns of meaning. In this method, the qualitative coding and categorising of the data involved dividing the data into small units and systematically refining them. Once this was achieved, the data were reviewed, which helped the researcher to obtain a global perspective of the content collected and the emerging themes. The more the researcher became familiar with the data, the better the data could be positioned (see Appendix 2).

According to Glaser (2002), descriptions are vague, and practitioners should follow a systematic process to explain their abstraction from the conceptual ability of time, place and people, to discover the enduring patterns that provide conceptual power. The process of open coding permits the researcher to use data from the first focus group or interview to conduct phrase-by-phrase or word-by-word analysis. This technique gives rise to initial insights and discovering which categories and themes within the data ought to be explored. 
To increase the objectivity of the interpretation of the data, two PhD graduates, who are also industrial-organisational psychologists, cross-examined the data. As there were no differences in their interpretation, this step confirmed that the researcher had arrived at a set of valid findings. The authors suggest that the initial procedure of coding and categorising is not sufficient for what will be discovered from empirical items (Henning et al., 2010).

The research took place in a large SOC that employs a diverse staff complement and transacts with multiple stakeholders. The sample selected was purposive, including five stakeholder groups consisting of non-management, managers, executives, customers and suppliers as illustrated in Table 1.

Where multiple stakeholder views are sought, economic, cultural, social, political, technological and environmental differences are likely to occur (Martin \& Barnard, 2013). Differences were observed in the social reality of the diverse sample regarding the phenomena being studied. According to Pearse and Kanyangale (2009), the researcher can apply a sufficiently increased level of interaction where the participants show a lower level of awareness of the concepts. This will ensure that the research study is a genuine output achievable through the eyes of multiple stakeholders.

Qualitative Delphi does not need to consider the use of a random sample, and in this study, the researcher did not aim to show statistically significant results. Most important is that the participants, namely the sample selected, are deemed experts based on their knowledge of the organisation, professional insight, and their interest in the problem being addressed (Habibi et al., 2014b). A purposive sample that has particular expertise increases the content validity of the research study. In other words, representation is not the objective for selecting individuals, expertise is (Avella, 2016).

\section{Phase 1: Focus groups and interviews}

Three pilot focus groups were conducted to quality assure the design, time allocated, feasibility of questions scripted and test the overall practicality of the process. There were no uncertainties raised and no refinements were made.

The researchers used a script of open-ended questions that follow, to hear the experiences of the groups:
1. What are the desirable and undesirable attributes that make the leadership of an organisation effective or ineffective, based on your perception?

2. What constitutes a quality relationship found in SC, for each of the stakeholder groups and the organisation from the perspective of both parties? What does each stakeholder want from the other?

3. What are the hard and soft factors that lead to OE? What will you say to the board?

During the interviews and focus groups, responses were captured and reviewed using handwritten notes, flipcharts and memos. The researcher typed up all transcriptions in Microsoft Excel, keeping track of the data recorded. The Excel spreadsheets were arranged according to the specific groups' names, namely, pilot, non-management, management, executives, customers and suppliers. Constant comparison of the data allowed the researcher to maintain theoretical sensitivity, stay close to the data and stimulate new thoughts and ideas about the incidents, concepts, categories and their properties. The differences or similarities were mainly as a result of stakeholder differences affected by experiences or timeframe (see Appendix 3). Authors advise that new and emerging themes may be arranged according to differences and similarities per stakeholder group (Bulawa, 2014). Glaser (2002) asserted that validity is obtained after there has been many fitting of words, and the chosen ones best represent the pattern and become valid and grounded.

Respondents participated in the meaning-making process by reflecting on what they had heard from each other during the focus group discussion. Face-to-face interviews, keeping the format consistent with focus groups, were implemented where the researchers could not gather a minimum of five participants, for example, the customer group.

Data were transcribed, coded and captured into Microsoft Excel (see Appendix 2). Through the process of content analysis, themes and patterns were identified until theoretical saturation was reached. Many undesirable categories, namely opposites, were found during the fieldwork. Frequent references were made, such as mistrust, the lack of communication or the lack of ethical behaviour. The researchers were mindful that this was recorded as trust, communication and ethical behaviour, to maintain a particular lens throughout. What emerged from the cumulative analysis of phase 1 was the developed model for the important PLAs, SC and OE themes proposed in Figure 1.

TABLE 1: Qualitative sample for phase 1.

\begin{tabular}{|c|c|c|c|c|c|c|}
\hline Stakeholder group & Pilot FG & Number ofparticipants & Focus groups & Number ofparticipants & Interviews & Number ofparticipants \\
\hline Non-management (S1) & 1 & 5 & 3 & 15 & 0 & - \\
\hline Managers (S2) & 1 & 7 & 4 & 25 & 0 & - \\
\hline Executives (S3) & 1 & 5 & 3 & 20 & 0 & - \\
\hline Customers (S4) & 0 & 0 & 1 & 4 & 3 & $4 \dagger$ \\
\hline Suppliers (S5) & 0 & 0 & 2 & 10 & 1 & 1 \\
\hline Total & 3 & 17 & 13 & 74 & 4 & 5 \\
\hline
\end{tabular}

Note: $\dagger$, In one customer interview, two participants contributed to the data. The abbreviation for stakeholder is depicted by the letter $\mathrm{S}$.

FG, Focus groups. 
The qualitative phase 1 was followed by the validation of the model by a panel of experts in phase 2 using a Delphi technique.

\section{Phase 2: Delphi technique}

A Delphi technique uses a self-administered survey asking experts to rank each item to reach consensus regarding the developed model. Six experts per stakeholder group were selected based on their knowledge and experience of the SOC, as well as sufficient awareness of the current context to make a decision about the proposed model and to comment on the themes. An important criterion was that all experts had a relationship of more than 5 years with the SOC and had dealings with the SOC over time. Experts were invited to participate via a WhatsApp call, giving brief reasons for their inclusion and getting their consent. All the instructions were captured in the same Excel spreadsheet attached in the email, which included a brief introduction of what is required by them. Participants were also emailed a consent form, which had to be completed.

A breakdown of the two samples can be seen in Table 2, round 1 and round 2 .

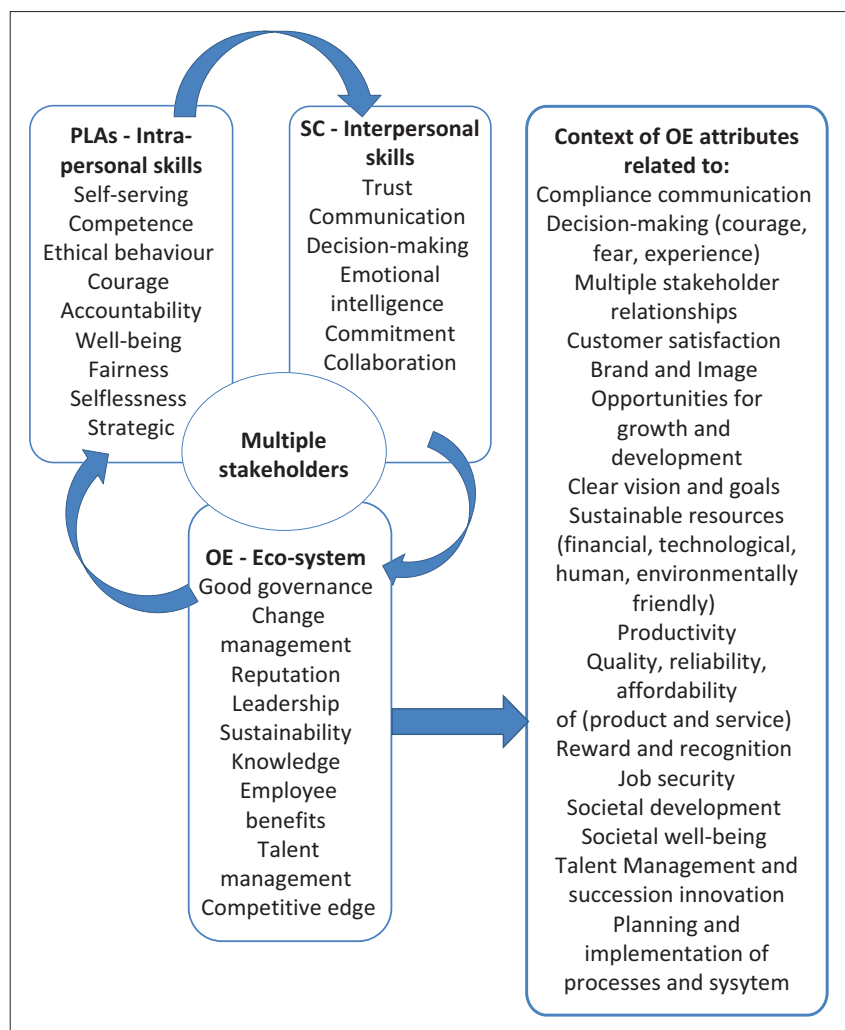

Note: The model illustrates the cyclical nature of the PLAs, SC and OE factors. On the righthand side, the context for how the OE items emerged is shown.

PLA, perceived leadership attributes; SE, social capital; OE, organisational effectiveness.

FIGURE 1: Conceptual model of the relationships between perceived leadership attributes, social capital and organisational effectiveness.
Authors recommend two or three rounds of iteration (Alghaffari et al., 2018) and reaching data saturation (Vonder Gracht, 2012). In this study, two rounds were sufficient to reach consensus and saturation.

\section{Delphi survey design}

A questionnaire, including four sections - namely biographical data, PLAs, SC and OE- was developed from the 24 themes that emerged from phase 1. Responses to the survey were elicited on a 7-point Likert-type scale starting from strongly disagree (1) to strongly agree (7). Each theme had a clear description and experts were invited to comment on their responses.

At the end of round 1, 10 new themes and descriptions were proposed, which were then included in the round 2 survey design. Each expert was presented with a detailed report of the consolidated results and was allowed to keep or change round 1 scores. They were asked to rank the refined survey, now consisting of 34 items, and volunteer any other comments. The survey was sent via an email. Excel was used for collecting and recording data, consolidating feedback and analysing the responses using mean scores, percentage consensus and capturing qualitative narratives. Final consensus was reached by 24 experts' representative of the stakeholder groups.

\section{Ethical considerations}

Industrial psychologists are ethically bound by standards set by the Health Professions Council of South Africa as well as international guidelines such as the American Psychological Association. The context and organisational setting of the study, namely an SOC, implies that the public has the right to know what has been researched. Ethical approval was obtained from the organisation and the academic institution where the study took place. Participation was voluntary and data were kept confidential.

\section{Results}

Phase 1

After conducting 13 focus groups and 5 interviews, on all stakeholder levels, data were rigorously analysed using thematic content analysis. Three main themes emerged from the data collected, one for each main concept. Intra-personal (PLAs) and inter-personal (SC) themes as well as themes relating to the eco-system $(\mathrm{OE})$ were identified. In total, there were 24 subthemes identified.

The themes which related to OE were complex, given the context of the organisation and current participant experiences. For example, participants believe that they will enjoy employee

TABLE 2: Qualitative sample phase 2.

\begin{tabular}{lccccc}
\hline Stakeholder group & Executives & Managers & Non-management & Customers & Suppliers \\
\hline Round 1 sample & 5 & 6 & 3 & 6 & 5 \\
Round 2 sample & 4 & 6 & 3 & 6 & 25 \\
\hline
\end{tabular}

Note: One executive did not return the round 2 survey. 
benefits relating to their job security, adequate rewards and recognition, which will in turn, impact their well-being and motivation, drive them to remain committed to the organisation and perform well. Ethical behaviour, trust, good governance and decision-making are all inter-related. For example, 'unethical behaviour' and the 'lack of co-operation involving processes and systems' in turn leads to 'mistrust'. Attributes that are embedded in the context which derived the OE themes are also themes derived in PLAs and SC.

The phase 1 results confirmed 24 themes, shown in Figure 1, to be validated in the model.

\section{Phase 2}

Consensus was determined by the percentage of experts in agreement and where a minimum of $60 \%$ majority rating was achieved (Habibi, Laroche, \& Richard, 2014a). The frequency of experts ranking an item ' 6 ' and ' 7 ' was counted. For example, 16 out of 25 experts accounted for an agreement of $64 \%$. Phase 2 results are represented in tables and substantiated by narratives to discuss the scores and view on consensus.

\section{Delphi round 1 results}

Twenty-five experts that included all stakeholder groups responded to round 1 and completed the survey fully. At this stage, the themes below $60 \%$ not reaching consensus were not yet removed (Hsu \& Sanford, 2007). The controlled feedback between rounds in the Delphi reduces the effect of researcher bias and ensures reliability (Creswell, 2014; Hsu \& Sanford, 2007). A breakdown of consensus reached in round 1 is shown in Table 3.

Nine PLAs were ranked, of which eight scored $60 \%$ consensus and above. There were six SC attributes, of which four scored $60 \%$ consensus and above, and nine OE factors, of which seven scored $60 \%$ consensus and above. Non-consensus items are shown by scores less than $60 \%$. An extract of qualitative comments, from experts in round 1 , indicates the complexity of the themes.

Extract of the qualitative comments in round 1: There is an indication that the organisation is under severe pressure and cannot respond effectively to many of the conditions required for desirable PLAs, SC and OE. Internal experts said the lack of competent leadership, self-serving behaviours, toxic culture and constant pressure has an impact on employee well-being and the overall morale of the employees. External experts expressed their dissatisfaction by saying the organisation is expecting us to be selfless referring to service and contracts.

Insights from the expert comments in phase 2 provide indications of differences and similarities amongst stakeholders (Appendix 4). Experts were asked to provide additional themes and descriptions relevant to include in the survey. They proposed 10 new themes as follows:
TABLE 3: Round 1 survey results in percentage for perceived leadership attributes, social capital and organisational effectiveness.

\begin{tabular}{|c|c|}
\hline Themes & Round 1 ranking $(\%)$ \\
\hline \multicolumn{2}{|l|}{ PLA } \\
\hline Courage & 84 \\
\hline Well-being & 84 \\
\hline Ethical behaviour & 80 \\
\hline Fairness & 72 \\
\hline Strategic & 72 \\
\hline Competence & 68 \\
\hline Accountability & 68 \\
\hline Self-serving & 64 \\
\hline Selflessness & 56 \\
\hline \multicolumn{2}{|l|}{ SC } \\
\hline Trust & 84 \\
\hline Communication & 84 \\
\hline Decision-making & 72 \\
\hline Commitment & 72 \\
\hline Emotional intelligence & 52 \\
\hline Collaboration & 36 \\
\hline \multicolumn{2}{|l|}{$\mathrm{OE}$} \\
\hline Reputation & 84 \\
\hline Employee benefits & 84 \\
\hline Good governance & 80 \\
\hline Change management & 80 \\
\hline Competitive edge & 80 \\
\hline Sustainability & 76 \\
\hline Talent management & 72 \\
\hline Leadership & 48 \\
\hline Knowledge & 40 \\
\hline
\end{tabular}

Note: Scores from $60 \%$ and above reached consensus and those below did not in round 1. PLA, perceived leadership attributes; SE, social capital; OE, organisational effectiveness.

- Perceived leadership attributes: Execution, influence, development, empathy.

- Social capital: Culture.

- Organisational effectiveness: State-owned companies' commitment, shareholder expectations, productive culture, continuous learning and positional leadership.

The new themes were added to the round 2 survey, as illustrated in Appendix 5.

\section{Delphi round 2 survey results}

After consolidating the collective results and preparing a controlled feedback report for each expert, the round 2 survey, now 34 items, was sent back to the experts. Each feedback report consisted of clear instructions which were to look at the collective scores, decides whether they would like to update their original score, score the new items and provide any further comments. Twenty-four experts responded in round 2. The themes that did not reach consensus after round 2 are illustrated and where relevant, removed from the final validated model.

A less than $15 \%$ change in the mean score of two distributions of results was deemed stable enough to stop further rounds. The scores from the new survey items showed a similar trend. Validity and rigour of phase 2 were substantiated by debate, giving relevance to the phenomenon being studied (Von der Gracht, 2012). 
TABLE 4: Survey items that reached consensus by the experts.

\begin{tabular}{lll}
\hline PLAs (10) & SC(5) & OE(10) \\
\hline Self-serving & Trust & Good governance \\
Ethical behaviour & Communication & Change management \\
Courage & Decision-making & Reputation \\
Accountability & Commitment & Sustainability \\
Well-being & Culture & Employee benefits \\
Fairness & - & Talent management \\
Strategic & - & Competitive edge \\
Execution & - & SOC commitments \\
Influence & - & Productive culture \\
Empathy & - & Positional leadership \\
\hline
\end{tabular}

PLA, perceived leadership attributes; SC, social capital; OE, organisational effectiveness; SOC, State-owned companies.

The final breakdown of the consensus reached after round 2 is shown in Table 4.

In the final round, there were three PLAs and two SC and four $\mathrm{OE}$ attributes that did not reach a $60 \%$ consensus score and should therefore be excluded from the model according to the expert feedback. Non-consensus items are shown in Appendix 6.

Based on the narratives quoted, slight refinements were made to the validated model. The experts were selected based on the same groups of multiple stakeholders, namely, non-management, management, executives, suppliers and customers and had to have a sound understanding of the SOC, given their tenure or relationship as supplier or customer. The highest-ranked items are courage, trust and reputation. The complexity of the relationships is discussed next.

Courage is linked to leadership influence: Amongst experts, $92 \%$ agree that leaders are currently crippled by fear and not willing to take a risk. This creates helplessness. To be able to step out of this will turn the morale around. The leadership tends to be leading by fear, authoritative and dictatorship and not by coaching and collaborating with others. Currently, it is not possible to have great courage standing up against the blatant wrong that is evident at the top, without fear of repercussions. The attribute 'courage' is multidimensional and when present can allow stakeholders to speak up. According to authors, courage refers to a combination of having the ability to tolerate high levels of uncertainty, show cultural adaptability, influence people who have different backgrounds and deal with change effectively (Avolio et al., 2009; House et al., 2014; Jacobson \& Anderson, 2015).

Trust is linked to collaboration in high-performing teams: Amongst experts, 92\% concurred that when trust exists, it will be the foundation of high performing teams and is currently a crucial element missing in leadership. Another asks, 'Where does an organisation start with rebuilding trust with multiple stakeholders when trust is low and has such a multifaceted perspective?' According to Willems et al. (2016), the concept of trust describes the perceived genuineness of an organisation, which is distinguished from the satisfaction that symbolises a particular stakeholder relationship.

Reputation is linked to leadership: Amongst experts, 96\% confirm the organisation is hiding behind bureaucracy and refraining from introducing innovative solutions. It appears they want to protect personal architecture or legacies and reputation is now non-existent. There is constant negative media coverage, impacted directly by its inability to provide a secure and reliable service to industry and households. Stakeholders award reputation in recognition of quality relationships accumulated over time by leadership and given the advantage of having gained social approval by doing the right thing (Kwon \& Adler, 2014). Having a good reputation, therefore, serves as an intangible resource embedded in the social context of an organisation (Zavyalova et al., 2016).

Given insights from the narratives and inductive reasoning, three slight refinements were justified to the model. That is:

- add collaboration

- change productive culture to culture

- change positional leadership to leadership.

Collaboration exists where there is a mutual understanding of the job to be performed, teamwork and a desire to succeed. Goa et al. (2016) asserted that the process of collaboration exists in factors that influence the culture, for example, differences in perceptions (House et al., 2014) that have impact. On the other hand, Cohen and Prusak (2001) proposed that trust, mutual understanding of shared values and attributes that bind members of human networks and communities, make co-operative action possible.

Multiple stakeholders confirm the organisational culture of the SOC is as a result of several internal and external factors. Therefore, organisational culture cannot be confined to productivity alone. Culture in this instance comes with legacy, political agendas as well as the goodwill that still exists with those who have selflessly given of themselves to make the SOC succeed. Organisational culture is nuanced by a dynamic interplay of both the observable tangibles and invisible intangibles from multiple perspectives.

The expert panel selected confirmed that leadership must involve all stakeholders in consultation to help turn the SOC around and to ensure, collaboration is improving because the new leadership is addressing this. Therefore, positional leadership in OE was replaced by leadership that participates in quality relationships, role modelling desirable attributes. The PLAs are influenced by factors beyond position, for example, psychological maturity and values (Haynes et al., 2015). The final model is illustrated in Figure 2.

Figure 2 confirms the connections and cyclical relationships between the three concepts, PLAs, SC and OE. The model confirms that there are PLAs which impact SC, which impacts $\mathrm{OE}$ and vice versa. The brown lines in the table signify how 


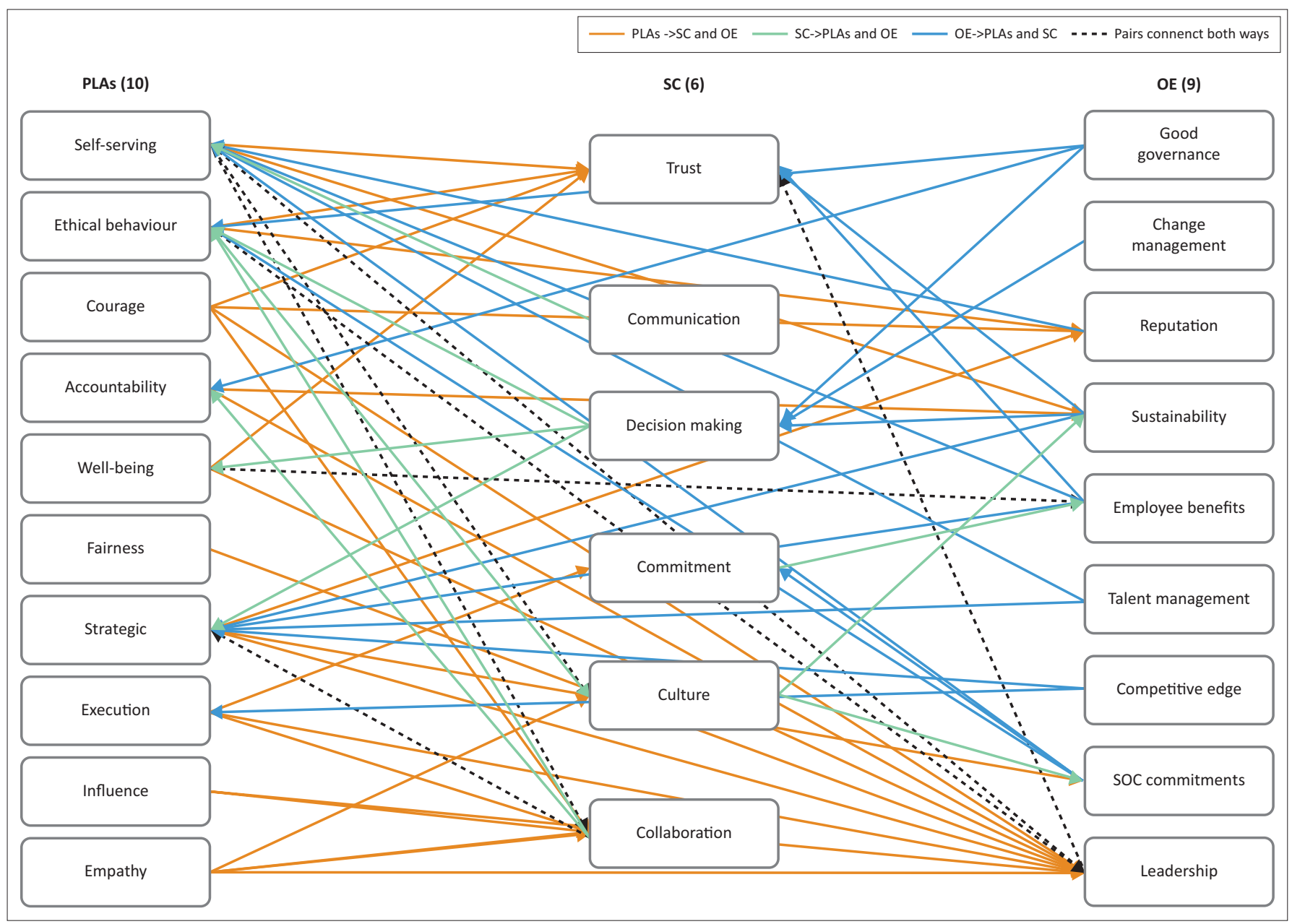

PLA, perceived leadership attributes; SC, social capital; OE, organisational effectiveness; SOC, State-owned companies.

FIGURE 2: Final validated model.

the PLAs are connected to SC and OE. For example, well-being connects with trust and leadership. The green lines signify how SC is connected to PLAs and OE. For example, organisational culture connects with ethical behaviour and sustainability. The blue lines signify how the OE is connected to PLAs and SC. For example, good governance connects with decision-making and accountability. The black dotted line signifies the combinations connecting both ways. For example, self-serving is connected to leadership and vice versa. The PLAs, SC and OE factors are the combinations shown both ways, as illustrated in Appendix 7.

This is significant in explaining the cyclical relationships in the model and the complexity of the relationships in the three major concepts, all of which has led to the current entropy the SOC finds itself in.

\section{Discussion}

The manifestation of the relationships found is a testament to the intensity of the challenges faced by the SOC. There are themes in the model that stood out in terms of the relationships, for example, self-serving, strategic, courage, trust, organisational culture, collaboration, leadership, reputation and sustainability. This discussion highlights the complexity and dominant associations found between PLAs, SC and OE. The narratives indicate the voices of the experts as they contributed to the Delphi survey debate.

\section{Relationships between perceived leadership attributes, social capital and organisational effectiveness}

Leadership stood out to be a key contributor to OE and has been linked to all of the PLAs shown in Appendix 8. During the expert debate, leadership was linked to self-serving and ethical behaviour and they are described as the culprits responsible for the ineffectiveness of the SOC. Experts confirmed, only a select few are continuously being selected, and most of the same select few have been found to have had corrupt dealings.

Internal and external stakeholders have provided different examples of their perception of leadership. Internal experts confirmed that most of the leadership is in self-preservation mode and acts in self-interest even though it is to the detriment of others at the company. Similarly, external experts assert that in underperforming entities, leadership has a tendency to protect their turf, stifling innovation and competitive ways of doing things. 
Leadership has been linked to the PLA, 'being strategic' which has been linked to decision-making found in quality relationships (SC). Decision-making has been linked to wellbeing and good governance and change management: factors found in OE. The majority of experts agree that leadership have not been strategic in matters that would serve the company or the country. However, a more sceptical view from experts indicates that they were quite strategic when enriching themselves and the Strategy for self-enrichment was brilliantly executed. The discussion highlights that where the leadership has been self-serving, the act of being strategic was not about building quality relationships that would increase SC. In this instance, when leadership has been strategic, it was about fostering corrupt relationships that would serve individual needs rather than leading to $\mathrm{OE}$.

It will be an important task for the collective leadership when receiving the feedback to apply introspection (Warren, 2016). This was echoed by the participants, where they started questioning the opportunity arising for greater introspection by the leadership. Participants believe if leadership is asking the right questions it would be the game-changer and that a means of inclusivity needs to be found. There exists a desire to be heard within the leadership, as was expressed by the internal stakeholders. However, where too much political involvement in the engine room is found, it may continue to prevent the satisfaction of multiple stakeholders.

A cyclical relationship between well-being and employee benefits and vice versa was established from the data analysis. Internal stakeholders feel threatened by rumours of job losses, missed opportunities for development, budget and headcount cuts. The threat of job security and psychological safety impacts how employee benefits are perceived. The voices of the experts confirm that the degree of emotional strain is linked to absenteeism, and low morale has driven lower performance; however, there are people being physically present but not mindful. The perception is that the absenteeism is more an indicator of poor management/leadership.

Although there is a view that most people in the organisation are incompetent, there is also the view from external stakeholders that the organisation should cut the fat. These stakeholders do not endorse the ongoing behaviours of self-interest which have prevented employees from feeling that their employee benefits are secure. The dissonance stems from the need for an effective turnaround strategy; however, the uncertainty of the suggested restructuring of the SOC has been challenging, especially when historically employee benefits were secured. According to Graaf et al. (2019), such uncertainty in public sector organisations can create additional strain on employees, often contributing to low morale and/or well-being.

Self-serving and strategic themes have a cyclical relationship with collaboration and culture, as described in SC. Experts agree that the culture in the organisation has changed: it isn't now what it was then. Organisational culture is impacted by the micro, meso and macro environment, and it has multiple stakeholder views of reality. Goa et al. (2016) asserted that the process of collaboration exists in the factors that influence culture. For example, motivated individuals will display attributes of will and ability, which are embedded in the team attributes that create the team culture. Furthermore, the structure and the relationships within the social network have a direct impact on the efficiency and the effectiveness of the performance culture (Goa et al., 2016).

Eradicating the corruption and creating a psychologically safe environment, free from fear, will shift the willingness of stakeholders to collaborate. However, self-serving leadership will continue to erode the trust, respect and mutual commitments of stakeholders (Avery \& Bergsteiner, 2011). Furthermore, experts claim, collaboration is not a value and those who captured the organisation were only interested in securing their own gains. On the other hand, there is a belief that the size of the organisation does not enable collaboration and teamwork; however, practices for increasing collaboration will help turn the ship around. According to Goa et al. (2016) and House et al. (2014), collaboration is an all-encompassing relational skill that starts with trust and contributes to the success of the organisation.

Stakeholders expect openness and honesty and transparency of information for the organisational leadership to be trusted. Multiple stakeholders must understand and know where the organisation is going, which will allow them to be aligned and achieve common goals. The author suggests that, where social knowledge has grown exponentially through sharing of information, there is a need to build a social climate based on trust, healthy competition and stakeholder co-operation (Buta, 2016). These attributes are characteristic in an organisation where the organisational culture cultivates high performance and collaboration (House et al., 2014).

Experts were in agreement that courage is linked to trust, collaboration, reputation and leadership. Leadership that lacks the courage to speak out and is constantly in fear of victimisation from top leadership is perceived undesirably, as the wrong-doing known to the public continues. Efforts of courageous leadership means doing something for the greater good, thereby, earning the trust of multiple stakeholders. Avery and Bergsteiner (2011) concurred that trust is a conscious practice, which is built through quality relationships and goodwill.

The theme strategic was found to be connected to talent management, sustainability, competitive edge and employee benefits. Given the downward spiral for a long while, there has been no strategic directional change which became more of a crisis. Experts confirm the SOC is not agile when it comes to innovation and change. Being strategic about talent management and sustainability, key drivers contributing to OE (Avery \&Bergsteiner, 2011), require consistency from collective leadership to lead effectively (Yukl, 2008). 
Apart from the fact that the leadership have to deal with the government in their engine room because of the SOC commitments, they also dont want to listen or include bottom-up strategic inputs. Instead, they continually insist on forcing down an uninformed recipe for disaster. Being strategic means the leadership understands that the value of having a good reputation, an intangible asset, develops with multiple stakeholders over a long-term period, for example by listening to their stakeholders. Furthermore, it is necessary that leadership understands what the factors are that constitute a good reputation (Baka, 2016; Zavyalova et al., 2016).

Reputation consists of intangible and tangible factors, and it either is affected by or affects PLAs and SC attributes. What stood out in this study is that there is a cyclical relationship between reputation and communication. There is constant negative media coverage, impacted directly by its inability to provide a secure and reliable service to industry and households, and ongoing bad practices are allowed which has a huge impact on trust of stakeholders. Zavyalova et al. (2016) asserted that having a good reputation aids the investment in SC, and it is achieved by rebuilding trust and the transparency of communication that benefits an organisation following a negative event. Others support the view that negative news in social media destroys trust, a key element of reputation (Habibi et al., 2014b).

Additionally, the organisation has removed reputation from its risk assessment processes, now deemed less important. The authors consider reputation as a strategic asset that significantly contributes to SC, and it is critical for future actions and decision-making in organisations (Baka, 2016; Zavyalova et al., 2016). Factors regarding rebuilding the reputation should be well understood by multiple stakeholders. Svenson et al. (2016) agreed that multiple stakeholders should be made aware of why some considerations for rebuilding reputation will be more important than others.

Whilst the experts did not explicitly link trust in SC back to 'self-serving' in PLAs, it appeared very strongly in the qualitative feedback during the data collection. Therefore, the link has been made. The mistrust was referred to as an input and output attribute. An extract from phase 1 refers: trust is an extreme variable. I can only trust you if you do as I say. When trust is broken - it should be measured and developed. Trust equals reputation. Trust is at the heart of a quality relationship which can create value in SC and OE (Fu et al., 2004; Putnam, 1995; Warren, 2016). Warren (2016) concurred, trust is perceived as a soft behavioural control which regulates relationships and the person who engenders trust must have a willingness to be vulnerable.

Multiple stakeholders have diverse needs for sustainability. Therefore, these differences should set the strategic context and decision-making that can be positively linked to OE. Authors concur that the leadership must align on what the purpose of the organisation is, and the values that multiple stakeholders can relate to that would support their purpose. Nonetheless, the purpose and values need to be visible and experienced or felt by the multiple stakeholders in the organisation, starting with actions by the leadership, who have others looking up to them, to be the role-models (Mansour et al., 2015; Warren, 2016).

It will take the entire leadership to steer the turnaround unlocking the intangibles and tangibles that are rooted in sustainability. Leadership must shift from self-interest to shared interest, founded on attributes of mutual obligations towards each other (Avolio et al., 2009). The intangibles are important for leadership to gain the co-operation of multiple stakeholders. Nohe et al. (2013) found an intangible asset, such as having genuine kindness and promoted by good values and an awareness of desirable PLAs, such as empathy and positive influence, has led to increased co-operation in the task amongst multiple stakeholders.

It is evident from this research that the tangible factor impacting $\mathrm{OE}$, according to external stakeholders, is the constant risk of higher costs [which] causes a lot of uneasiness. On the other hand, some of the external stakeholders said cost and pricing are not the issue. However, an effective turnaround strategy is important. The internal stakeholders assert that the shareholder (government) has more trouble recognising these issues, than providing support for an effective turnaround strategy. The challenge runs deep and changing the perception of multiple stakeholders will be difficult as it still appears reasons are being created to support personal agendas that are not in the interest of the public. Leadership must take accountability and make the right decisions regardless of uncertainty and risk.

Strategic direction involves a set of goals which can mobilise multiple stakeholders to act. Buta (2016) asserted that the norms, values, attitudes, beliefs and behaviours that lead to cooperative behaviours must have mutually beneficial collective actions for stakeholders of the organisation. It is in these circumstances that stakeholders show willingness for collaboration. Stakeholders (the experts) believe that the shareholder (government) should be assured of their investment, and the year-end results and targets should speak for itself. However, Graaf et al. (2019) concurred that talks of budget cuts in the public sector create added strain on employees. This triggers the uncertainty and contributes to the negative rumours and low morale of stakeholders (Graaf et al., 2019). In essence, the strategies the SOC designs for securing (reassuring) the sustainability of the employee benefits of internal stakeholders should help to regain trust. Engert and Baumgartner (2016) concurred that such strategies must be carefully designed to match specific SOC circumstances. Additionally, strategies need to be implemented with consistency, taking into consideration the SOC context and therefore continuous alignment with the organisation's goals, resources available and priorities and considering multiple stakeholder dynamics (Hadders, 2010). 
Given the current complexity in the SOC and particular industry, leadership should actively seek feedback from all stakeholders. This will instil a belief that their concerns have genuinely been considered and which will help to rebuild confidence (Akrofi, 2016; Jiang \& Liu, 2015). The active involvement of government in the day-to-day operations is perceived by many as a move towards internal corruption. Sustainability can be achieved with the right mix of SC attributes that places importance on the uniqueness of the social, economic, environmental, political and financial context, which assists in galvanising OE (Kwon \& Adler, 2014). Svenson et al. (2016) concurred this will provide the confidence that the organisation is being steered effectively towards the desired state of sustainability for the future.

Internal experts confirm, there is a slight improvement, which gives hope. However, the external experts claim that there are key aspects that must be addressed by leadership to get support from employees, customers and suppliers. According to Buta (2016), in SC, communication contributes to the quality of relationships and social context. Leadership unlocks this potential and helps to demonstrate the capacity to meet multiple stakeholder needs, which is the essence of a truly transformative organisation (Monnavarian \& Mostafa, 2009). Zavyalova et al. (2016) concurred, what the SOC leadership needs most right now is stakeholders who are able to filter negative information that leads to a bad reputation, and who have access to positive information to reach social approval again. Leadership must demonstrate that they are acting for the greater good and reinforce social equality, which serves the best interest of multiple stakeholders and has mutual benefit.

\section{Conclusion}

This study started out with the intent to test the relationships between PLAs, SC and OE. A critical literature study indicated that many of the themes underscored by the main concepts were either vague or not yet understood in the context of an SOC. Significant results and insight in understanding the phenomena have been achieved. Multiple stakeholders participated over two research phases, which led to the validation of the model.

The research methodology, namely adapted grounded theory, resembles an iterative approach whereby the researcher has to go back and forth to the data, and is required to stay open throughout the research study, thereby allowing the data to speak for itself. Given that the Delphi survey uses a quantitative approach, the researcher chose to substantiate the quantitative results by sharing the voices of the experts and to build on the themes validated.

There were a few limitations and future possibilities for this study. These are discussed next.

\section{Limitations}

Qualitative research allows for meaning to be derived from the experiences of the participants. However, including multiple stakeholders intensified the complexity of the themes, given similarities and differences. Consensus was calculated on the overall consolidated results, and it was difficult to maintain a single stakeholder perspective without the sophistication of statistical analysis. In such examples, the reviewer substantiated overall consensus referring to the debate and qualitative comments by the experts. Using an adapted grounded theory is not strictly in line with the analysis prescribed by pure grounded theory (Glaser, 1992). According to Glaser (2002), where descriptions have been vague, practitioners have an opportunity to explain the construct and share the context in order to increase the conceptual power. This may be an opportunity for a future study, given that this may have influenced the perception researchers have of the study, namely that the theoretical and paradigmatic underpinnings may be vague. Glaser (1978) confirmed that in theoretical sensitivity, participants may not have an empirical understanding of the theory; however, grounded theory as methodology goes beyond description and transcends into a bigger picture. The researcher has the accountability to abstract the theory into core variables by cutting back and ordering the concepts that lend credibility. There are no specific rules for the process of delimiting in the face of copious and lengthy data.

Delphi surveys are anonymous, and feedback is controlled. Therefore, experts could not debate their responses in a face-to-face setting in which they could reveal their unique stakeholder perspective. An enriched debate where each of the stakeholder concerns may be heard will enable opportunities for reflection on how they may be contributing to the problem, and then own and fix it.

The two-phased study was conducted over an extended period of time, which stifles a solution-driven mindset for scientific research. The SOC can no longer delay acknowledging the essential PLAs, gaining value from SC, which relates positively to $\mathrm{OE}$. The results of this study are not being circulated to the employees of the SOC or the public and this is potentially affecting an effective turnaround.

\section{Future possibilities for the state-owned company}

Everyone is responsible for helping turn the SOC around. Therefore, the onus rests on all stakeholders, in particular, for leadership to eradicate corruption, increase financial prudence and have the type of courage that nurtures quality relationships. Goodwill exists because stakeholders understand that the perceived lack of development opportunities is because of real financial constraints and the need for prioritising tasks rather than development. The willingness to make trade-offs will help meet the demands of all stakeholders now and into the future, without compromising capability or stifling courageous efforts.

This research has introduced a model accompanied by evidence of the tangibles and intangibles needed to enhance the work place through stakeholder co-operation. The 
opportunity to share this validated model most effectively must be established as a matter of urgency, and it is possible to build a case for collaboration as an important first capability to develop in the SOC (Appendix 9).

\section{Acknowledgements Competing interests}

The authors declare that they have no financial or personal relationships that may have inappropriately influenced them in writing this article.The authors have declared that no competing interests exist.

\section{Authors' contributions}

S.T. is the main author. She is the main contributor to collecting and analysing the data and writing the article, as part of her PhD study. C.H. is the supervisor of the study and contributed in the conceptualisation, revision and editing of the article.

\section{Ethical considerations}

Ethical clearance, reference number IPPM-2017-123 (D), has been granted by the Ethical Committee of the Department of Industrial Psychology and People Management, University of Johannesburg.

\section{Funding information}

This research received no specific grant from any funding agency in the public, commercial or not-for-profit sectors.

\section{Data availability}

Data are sensitive in nature, but if a reasonable request is made it can be made available.

\section{Disclaimer}

The views and opinions expressed in this article are those of the authors and do not necessarily reflect the official policy or position of any affiliated agency of the authors.

\section{References}

Adler, P.S., \& Kwon, S. (2002). Social capital: Prospects of a new concept. Academy of Management Review, 27(1), 17-40. https://doi.org/10.5465/amr.2002.5922314

Akrofi, S. (2016). Evaluating the effects of executive learning and development on organisational performance: Implications for developing senior manager and executive capabilities. International Journal of Training and Development, 20(3), 177-199. https://doi.org/10.1111/ijtd.12082

Alghaffari, S., Nguyen, H., \& Chen, P.S. (2018). Critical factors in organisational effectiveness: The case of Saudi Arabian seaports. Journal of Sustainable
Development of Transport and Logistics,3(2), 49-65. https://doi.org/10.14254/ Development of

Anney, V.N. (2014). Ensuring the Quality of the Findings of Qualitative Research: Looking at Trustworthiness Criteria. Journal of Emerging Trends in Educational Research and Policy Studies, (5)2, 272-281. Retrieved from https://www.google. com/search?q=Anney\%2C+V.N.+(2014)

Avella, J.R. (2016). Delphi panels: Research design, procedures, advantages, and challenges. International Journal of Doctoral Studies, 11, 305-321. https://doi. org/10.28945/3561

Avery, G.C., \& Bergsteiner, H. (2011).Sustainable leadership practices for enhancin business resilience and performance. Strategy \& Leadership, 39(3), 5-15. https:// doi.org/10.1108/10878571111128766
Avgar, A.C. (2010). Negotiated capital: Conflict, its resolution, and workplace social capital. International Journal of Conflict Management, 21(3), 236-259. https:// doi.org/10.1108/10444061011063162

Avolio, B.J., Walumba, F., \& Weber, T. (2009). Leadership: Current theories, research, and future directions. Annual Review of Psychology, 60, 421-449. https://doi. org/10.1146/annurev.psych.60.110707.163621

Baka, V. (2016). Formative reputation: From being an organisational asset to becoming a process in the making. Corporate Reputation Review, 19(2), 152-165. https:// doi.org/10.1057/crr.2016.4

Bryant, A., \& Charmaz, K. (2007). Grounded theory research: Methods and practices. In A. Bryant \& K. Charmaz (Eds.), The Sage handbook of grounded theory (pp. 1-28). London: Sage.

Bulawa, P. (2014). Adapting grounded theory in qualitative research: Reflections from personal experience. International Research in Education, 2(1), 79-114. https:// doi.org/10.5296/ire.v2i1.4921

Buta, S. (2016). The social capital: From macro to micro economic. The USV Annals of Economics and Public Administration, 16(1), 138-144.

Charmaz, K. (2006). Constructing grounded theory: A practical guide through qualitative analysis. London: Sage.

Clarke, J.R., Murphy, C., \& Singer, S.J. (2014). When do leaders matter? Ownership, governance and the influence of CEOs on firm performance. The
Leadership Quarterly, 25(2), 358-372. https://doi.org/10.1016/j.leaqua.2013. Leadership
09.004

Cohen, D., \& Prusak, L. (2001). In good company: How social capital makes organisations work. In Harvard Business Press (pp. 1-21). Retrieved from http:// organisations work. In Harvard Business Press
www.andreabiancalani.it/InGoodCompany.pdf

Commission of Inquiry into State Capture. (2020). The Judicial Commission of inquiry into allegation of State capture. Corruption and fraud in the public sector including organs of State. Retrieved from https://www.statecapture.org.za/

Creswell, J.W. (2014). Research design: Qualitative, quantitative and mixed methods approaches (4th edn.). Thousand Oaks, CA: Sage.

Engert, S., \& Baumgartner, R. (2015). Corporate sustainability strategy - Bridging the gap between formulation and implementation. Journal of Cleaner Production, 113, 822-834. https://doi.org/10.1016/j.jclepro.2015.11.094

Fu, Q., Stephenson, M., \& Ebrahim, C. (2004). Trust, social capital, and organizational effectiveness (pp. 1-44). Blacksburg, VA: University of Virginia. Retrieved from https://www.researchgate.net/publication/251443327_Trust_Social_Capital_ and_Organizational_Effectiveness/citation/download

Fukuyama, F. (2001). Social capital, civil society and development. Third World Quarterly, 22(1), 7-20. https://doi.org/10.1080/713701144

Geldenhuys, C.A., \& Veldsman, T.H. (2011). A change navigation based, scenario planning process within a developing world context from an Afro-centric leadership perspective. SA Journal of Human Resource Management, 9(1), 1-17. https://doi.org/10.4102/sajhrm.v9i1.265

Gholami, Y., \& Salimi, Y. (2014). Evaluation of quantitative measurement and reporting of social capital in organisations. Academic Journal of Research in Economics and Management, 2(2), 51-57. https://doi.org/10.12816/0006533

Glaser, B.G. (1978). Theoretical sensitivity: Advances in the methodology of grounded theory. Mill Valley, CA: Sociology Press.

Glaser, B.G. (1992). Basics of grounded theory analysis: Emergence vs. forcing. Mill Valley, CA: Sociology Press.

Glaser, B.G. (2002). Conceptualization: On theory and theorizing using grounded theory. International Journal of Qualitative Methods, 1(2), 23-38. https://doi. org/10.1177/160940690200100203

Glaser, B.G., \& Strauss, A. (1967). Discovery of grounded theory: Strategies for qualitative research. Nursing Research, 17(4), 364. https://doi. org/10.1097/00006199-196807000-00014

Goa, S., Guo, Y., Chen, J., \& Li, L. (2016). Factors affecting the performance of knowledge collaboration in virtual team based on capital appreciation. Information Technology Management, 17(2), 119-131. https://doi.org/10.1007/ s10799-015-0248-y

Graaf, G., Hengeveld-Bidmon, E., \& Carnochan, S. (2019). Change communication in public sector cutback management. Public Organization Review, 19, 453-472. https://doi.org/10.1007/s11115-018-0408-8

Habibi, A., Sarafrazi, A., \& Izadyar, S. (2014b). Delphi technique theoretical framework in qualitative research. The International Journal of Engineering and Science, 3(4) 8-13. Retrieved from https://scholar.google.co.za/scholar?q=habibi, +sarafrazi+\% $26+i z a d y a r,+2014+c i t e \& h l=e n \& a s \_s d t=0 \& a s \_v i s=1 \& o i=s c h o l a r$

Habibi, M.R., Laroche, M., \& Richard, O.M. (2014a). The roles of brand community and community engagement in building brand trust on social media. Computers in Human Behavior, 37, 152-161. https://doi.org/10.1016/j.chb.2014.04.016

Hadders, H. (2010). The adaptive quadruple bottom line scorecard: Measuring organisational sustainability performance. Retrieved from http://www.csin-rcid. ca/downloads/csin_conf_henk_hadders.pd

Harter, J. (2015). Introduction: History in the study of leadership. Journal of Leadership Studies, 9(2), 1-22. https://doi.org/10.1002/jls.21362

Haynes, K., Hitt, M., \& Campbell, J. (2015). The dark side of leadership: Towards a mid-range theory of Hubris and Greed in entrepreneurial contexts: The dark side of leadership. Journal of Management Studies, 52(4), 479-505. https://doi org/10.1111/joms.12127

Henning, E.H., Van Rensburg, W., \& Smith, B. (2010). Finding your way in qualitative research. Pretoria: VanSchaik Publishers. 
Hofstede, G. (1980). Culture's consequences - International differences in workrelatedvalues. Beverly Hills, London: Sage.

House, R.J., Dorfman, P.W., Javidan, M., Hanges, P.J., \& Sully de Luque, M.F. (2014) Strategic leadership across cultures: The GLOBE study of CEO leadership behaviour and effectiveness in 24 countries. Los Angeles, CA: Sage.

Hoxha, A. (2015). Empowerment and trust as mediators of the relationship between transformational leadership and organisational effectiveness. European Journal of Economic and Political Studies, 8, 43-60. Retrieved from https://www.researchgate. net/profile/Agron Hoxha2/publication/337485685_Empowerment and Trust as_Mediators_of_the_Relationship_between Transformational Leadership and Organizational-Effectiveness/links/5ddb7891458515 dōc2f4b7c06/ Empowerment-and-Trust-as-Mediators-of-the-Relationship-betweenTransformational-Leadership-and-Organizational-Effectiveness.pdf

Hsu, C., \& Sandford, B.A. (2007). The Delphi technique: Making sense of consensus, practical assessment. Research and Evaluation, 12, 10. https://doi.org/10.7275/ pdz9-th90

Hussein, M., Kennedy, A., \& Oliver, B. (2017). Grounded theory and the Conundrum of literature review. The Qualitative Report, 22(4), 1199-1210.

Inglehart, R., \& Carballo, M. (1997). Does Latin America exist? (And is there a Confucian culture?): A global analysis of cross-cultural differences. PS: Political Confucian culture?): A global analysis of cross-cultural differen
Science \& Politics, 30(1), 34-47. https://doi.org/10.2307/420668

Jacobson, C.B., \& Anderson, L.B. (2015). Is leadership in the eye of the beholder? A study of intended and perceived leadership practices and organisational performance. Public Administration Review, 75(6), 829-841. https://doi.org/10.1111/puar.12380

Jiang, J.Y., \& Liu, C.W. (2015). High performance work systems and organisational effectiveness: The mediating role of social capital. Human Resource Management Review, 25(1), 126-137. https://doi.org/10.1016/j.hrmr.2014.09.001

Juvekar, A., \& Pandey, S. (2017). Usage of balance scorecard in Information Technology Industry. Global Journal of Mathematical Sciences: Theory and Practical, 9(2), 205-224.

Kwon, S., \& Adler, P.S. (2014). Social capital: A maturation of a field of research. Academy of Management Review, 39(4), 412-422. https://doi.org/10.5465/ amr.2014.0210

Lawler, E.E. (2014). Sustainable effectiveness and organization development: Beyond the triple bottom line. OD Practitioner, 46(4), 65-67. Retrieved from https:// the triple bottom line. OD Practitioner, 46(4), 65-67. Retrieved from https:// Effectiveness_Org_Development.pdf

Lins, K.V., Servaes, H., \& Tamayo, A. (2017). Social capital, trust, and firm performance: The value of corporate social responsibility during the financial crisis. The Journa of Finance, $72(4), 1785-1824$. https://doi.org/10.1111/jofi.12505

Lord, R.G., Day, D.V., Zaccaro, S.J., Avolio, B.J., \& Eagly, A.H. (2017). Leadership in applied psychology: Three waves of theory and research. Journal of Applied Psychology, 102(3), 434-451. https://doi.org/10.1037/apl0000089

Mansour, H.F., Heath, G., \& Brannan, M.J. (2015). Exploring the role of HR practitioners in pursuit of organizational effectiveness in higher education institutions. Journal of Change Management, 15(3), 210-230. https://doi.org/10.1080/14697017.20 15.1045539

Martin, J. (2019). The leadership/followership process: A different understanding of library leadership. The Journal of Academic Librarianship, 45(1), 15-21. https:// doi.org/10.1016/j.acalib.2018.11.004

Martin, P., \& Barnard, A. (2013). The experience of women in male-dominated occupations: A constructivist grounded theory inquiry. SA Journal of Industria Psychology, 39(2), a1099, 12 pages. https://doi.org/10.4102/sajip.v39i2.1099

Mikelsone, E., \& Liela, E., 2016, Idea management and organisational effectiveness: A research gap. Journal of Business Management,5(2), 4-23. Retrieved from google. $\mathrm{com} /$ search? ? =Mikelsone $\% 2 \mathrm{C}+\mathrm{E} .+\% 26+$ Liela $\% 2 \mathrm{C}+\mathrm{E} . \% 2 \mathrm{C}+2016 \% 2 \mathrm{C}+{ }^{\prime}$ Idea+mana

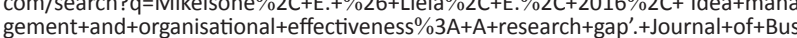
iness+Management+12\%2C+p.9+(4-23)\&rlz=1C1GCEJ enZA889ZA890\&oq=Mike iness+Management+12\%2C+p.9+(4-23)\&rlz=1C1GCEJ_enZA889ZA890\&oq=Mike Isone $\% 2 \mathrm{C}+\mathrm{E} .+\% 26+L i e l a \% 2 \mathrm{C}+\mathrm{E} . \% 2 \mathrm{C}+2016 \% 2 \mathrm{C}+$ Idea+management+and+organ
sational+effectiveness $\% 3 \mathrm{~A}+\mathrm{A}+$ research+gap'.+Journal+of+Business+Management

Monnavarian, A., \& Mostafa, A. (2009). Intrapreneurship: The role of social capital Empirical evidence and proposal of a new model of intrapreneurship and its relationship with social capital. Business Strategy Series, 10, 383-399. https://doi. relationship with social capital. Busine

Nadkarni, D., \& D'Souza, M. (2015). A study of the success value of the four approaches to organisational effectiveness in 18 companies in the Indian service and industry sectors. Journal of Management, 11(1), 77-89. Retrieved from http://www. iosrjournals.org/iosr-jbm/papers/Conf.17016-2017/Volume\%201/11.\%2077-89.pdf

Nahapiet, J., \& Ghoshal, S. (1998). Social capital, intellectual capital, and the organizational advantage. Academy of Management Review, 23(2), 242-266. https://doi.org/10.5465/amr.1998.533225

Nienaber, H., \& Svenson, G. (2013). An analysis of the contribution of leadership to organisational performance using complexity science. Journal of Management Development, 32(8), 836-851. https://doi.org/10.1108/JMD-08-2011-0101

Nohe, C., Michaelis, B., Menges, J.I., Zhang, Z., \& Sonntag, K. (2013). Charisma and organisational change: A multilevel study of perceived charisma, commitment to change, and team performance. The Leadership Quarterly, 24,378-389. https:// doi.org/10.1016/j.leaqua.2013.02.001

Pearse, N., \& Kanyangale, M. (2009). Researching organizational culture using the grounded theory method. The Electronic Journal of Business Research Methods, 7, 67-74. Retrieved from www.ejbrm.com

Public Protector, State of Capture. (2016). A report by the public protector. No. 6 pp. 1-335. Retrieved from https://www.sahistory.org.za/archive/state-capturereport-public-protector-14-october-2016
Putnam, R.D. (1995). Bowling alone: America's declining social capital. Journal of Democracy, 6(1), 65-78. Retrieved from http://www.socialcapitalgateway.org/ content/paper/putnam-r-d-1995-bowling-alone-americas-declining-socialcontent/paper/putnam-r-d-1995
capital-journal-democracy-6-1-

Raelin, J.A. (2018). What are you afraid of: Collective leadership and its learning implications.Management Learning, 49(1), 59-66. https://doi. org/10.1177/1350507617729974

Read, E.A. (2013). Workplace social capital in nursing: An evolutionary concept analysis. Journal of Advanced Nursing, 70(5), 997-1007. https://doi.org/10.1111/jan.12251

Robertson, I.T., Callinan, M., \& Bartram, D. (Eds.). (2002). Organizational effectiveness: The role of psychology. ProQuest Ebook Central. https://ebookcentral.proquest.com

Sargis-Roussel, C., Belmondo, C., \& Deltour, F. (2017). Bringing people back in: How group internal social capital influences routines'emergence.European Management Review, 14, 101-112. https://doi.org/10.1111/emre.12100

Schwartz, S.H. (1999). A theory of cultural values and some implications for work. Applied psychology: An International review, 48(1), 12-47. https://doi. org/10.1111/j.1464-0597.1999.tb00047.x

Shenton, A. K. (2004). Strategies for Ensuring Trustworthiness in Qualitative Research Projects. Education for Information, 22, 63-75. https://doi.org/10.3233/EFI-200422201

Smith, P.B., Dugan, S., \& Trompenaars, F. (1996). National culture and the values of organizational employees - A dimensional analysis across 43 nations. Journal of Cross-Cultural Psychology, 27(2), 231-264. https://doi.org/10.1177/ 0022022196272006

Sohmen, V.S. (2015). Reflections on creative leadership. International Journal of Global Business, 8(1), 1-14. https://doi.org/10.13140/RG.2.1.1620.3366

Stoughton, A.M., \& Ludema, J. (2012).The driving forces of sustainability Journal of Organizational Change Management, 25(4), 501-517. https://doi. Journal of Organizational Change
org/10.1108/09534811211239191

Svenson, G., Høgevold, N.M., Petzer, D., Padin, C., Ferro, C., Klopper, H.B., ... Wagner, B. (2016). Framing stakeholder considerations and business sustainability efforts: A construct, its dimensions and items. Journal of Business \& Industrial Marketing,31(2), 287-300. https://doi.org/10.1108/JBIM-05-2014-0094

Tantardini, M., \& Kroll, A. (2015). The role of organizational social capital in performance management. Public Performance \& Management Review, 39(1), 83-99. https://doi.org/10.1080/15309576.2016.1071163

Treharne, G.J., \& Riggs, D.W., (2014) Ensuring quality in qualitative research. In P. Rohleder \& AC. Lyons (eds.), Qualitative Research in Clinical and Health Psychology (pp. 57-73). Basingstoke: Palgrave Macmillan. https://doi. org/10.1007/978-1-137-29105-9_5

Udayaadithya, A., \& Gurtoo, A. (2014). Effectiveness of local governance: interactions between social capital and institutional structures. Asian Social Work and Policy Review, 8(1), 71-95. https://doi.org/10.1111/aswp.12026

Veldsman, T.H., \& Johnson, A.J. (2016). Leadership: Perspectives from the front line. Randburg, Johannesburg: KR Publishing.

Von der Gracht, H.A. (2012). Consensus measurement in Delphi studies: Review and implications for future quality assurance. Technological Forecasting and Socia Change, 79(8), 1525-1536. https://doi.org/10.1016/j.techfore.2012.04.013

Warner, J. (2012). Social capital and IS Leadership: A conceptual framework. Academy of Information and Management Sciences Journal,15(1), 85-98. Retrieved fromhttps://www.academia.Edu/25667456/Social_Network_Based Leadership Decision Making_Supported_By_Social_Capital_Knowledge_Management and Emotional_Intelligence

Warren, J.S. (2016). The case for trust as a soft or behavioral control for organizational effectiveness (OB).Academy of Business Research Journal, 2, 59. Retrieved from https://search.proquest.com/docview/1863560945?pq-origsite=gscholar\&fromop enview=true\#

Willems, J., Jegers, M., \& Faulk, L. (2016). Organisational effectiveness reputation in the non-profit sector. Public Performance and Management Review, 39(2), 476-497. https://doi.org/10.1080/15309576.2015.1108802

Willig, C. (2009). Introducing qualitative research in psychology. McGraw-hill education (UK)

Young, Y. (2014). Social context and social capital: Governance, inequality, and the individual experience. International Journal of Sociology, 44(2), 37-62. https:// doi.org/10.2753/IJS0020-7659440202

Yukl, G. (2008). How leaders influence organisational effectiveness. The Leadership Quarterly, 19(6), 708-722. https://doi.org/10.1016/j.leaqua.2008.09.008

Yukl, G. (2012). Effective leadership behaviour: What we know and what questions need more attention. Academy of Management Perspectives, 26(4), 66-85. https://doi.org/10.5465/amp.2012.0088

Zadeh, H.H., Feizi, M., \& Alipour, H. (2013). Surveying the relationship between social capital and knowledge management implementation at Custom House of Imam Khomeini Port. Journal of Business Management and Social Sciences Research, 2(10), 65-66. Retrieved from https://www.semanticscholar.org/paper/Surveyingthe-Relationship-between-Social-Capital-Feizi-Zadeh/54fe76dd7b1d806149c7ed 08b7cc4d726f387346

Zavyalova, A., Pfarrer, M.D., Reger, R.K., \& Hubbard, T.D. (2016). Reputation as a benefit and a burden? How stakeholders' organisational identification affects the
role of reputation following a negative event. Academy of Management Journal, role of reputation following a negative event. Academy of
59(1), 253-276. https://doi.org/10.5465/amj.2013.0611

Zoogah, D.B, Peng, M.W., \& Woldu, H. (2015). Institutions, resources, and organisational effectiveness in Africa. The Academy of Management Perspectives, 29(1), 7-31. https://doi.org/10.5465/amp.2012.0033 


\section{Appendix 1}

TABLE 1-A1: Provisions made to ensure quality research.

\section{Criterion with a brief description}

Credibility - Do findings represent the views and feelings of all participants

Transferability - Will the findings of this study be applicable in other contexts

Dependability - Would another researcher conducting the same study, produce similar results

Confirmability - Do the findings genuinely represent the participants' responses, or are they influenced by the researcher's biases, motivations and interests

Authenticity - Do the findings represent differing viewpoints and have transformative potential and are useful for further action

\section{The approach implemented by the researcher to ensure trustworthiness and good quality}

Focus groups were homogeneous in nature, and the topic solicited personal perceptions about the concepts. The researcher had to look out for possible friendship groups, sudden experts and uncooperative participants, and prevent private conversations that could increase group think (Willig, 2009). The strength of the focus group was in the ability of the researcher to create a safe space for mobilising participants to comment on each other's experiences without any one individual dominating the conversation. Willig (2009) claimed, asking the right questions will improve the validity of the findings.

The sample is purposive and includes five levels of internal and external stakeholder groups. A diverse sample increased the in-depth results, which indicated the differences and similarities amongst stakeholders. The context of the SOC reflects a unique social reality for which appreciation was necessary by the researcher. Shenton (2004) questioned whether the idea of producing truly transferable results is a realistic aim in a single qualitative study.

Focus groups were planned and executed at the outset. The researcher conducted face-to-face interviews with individuals, when it became necessary. The process is written up clearly in the methodology and the results section. The interviews garnered the same results as the focus groups. This level of transparency will allow other researchers to adopt a similar approach to data collection in their studies. An audit trail (Anney, 2014) is available, should any questions or challenges arise.

According to Shenton (2004), the findings must reflect the view of the respondents rather than that of the researcher. The two-phased qualitative approach was adopted to achieve the following: (1) develop a model after taking into consideration the stakeholder views; (2) validate the model using a Delphi technique. The most important measure of integrity is when others believe that there are no fabrications of the data (Anney, 2014).

Like grounded theory, adapted grounded theory is not very prescriptive. It may present the researcher with the risk, particularly where there is no consensus in the findings. Therefore, the researcher applied specified steps and continuously gauged the study progress, with the ultimate goal of delivering a legitimate research report. Where changes are required, as per grounded theory principles, authors encourage researchers to make these changes; it was advisable for the researcher to develop a blueprint that will aid in responding to the research question (Willig, 2009).

Source: Treharne, G.J., \& Riggs, D.W. (2014). Ensuring quality in qualitative research. In P. Rohleder \& AC. Lyons (Eds.), Qualitative Research in Clinical and Health Psychology (pp. 57-73). Basingstoke: Palgrave Macmillan. https://doi.org/10.1007/978-1-137-29105-9_5

SOC, State-owned companies.

\section{Appendix 2}

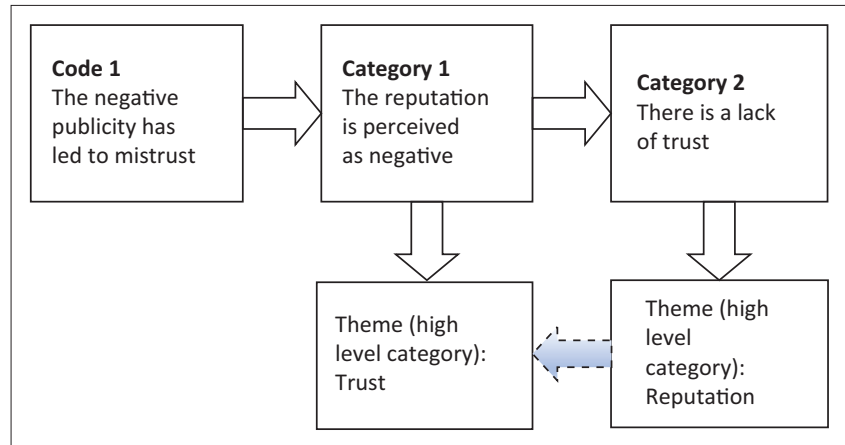

FIGURE 1-A2: Illustration of the coding approach using an adapted version of grounded theory.

Source: Adapted from Henning, E.H., Van Rensburg, W., \& Smith, B. (2010). Finding your way in qualitative research. Van Schaik Publishers: Pretoria.

\section{Appendix 3}

TABLE 1-A3: Illustration of similar and different themes for internal and external stakeholders.

\begin{tabular}{|c|c|c|}
\hline \multirow[t]{2}{*}{$\begin{array}{l}\text { Similarities and } \\
\text { differences }\end{array}$} & \multicolumn{2}{|c|}{$\begin{array}{l}\text { Comparison of internal and external stakeholder theme } \\
\text { (PLAs, SC and OE) }\end{array}$} \\
\hline & Internal stakeholders & External stakeholders \\
\hline \multirow[t]{14}{*}{ Similarities } & Trust & Trust \\
\hline & Communication & Communication \\
\hline & Competence & Competence \\
\hline & Governance & Governance \\
\hline & Decision-making & Decision-Making \\
\hline & Compliance & Compliance \\
\hline & Sustainability & Sustainability \\
\hline & Timeous payment & Timeous payment \\
\hline & Leadership & Leadership \\
\hline & Collaboration & Collaboration \\
\hline & Accountability & Accountability \\
\hline & Fairness & Fairness \\
\hline & Reputation & Reputation \\
\hline & Productivity & Productivity \\
\hline \multirow[t]{21}{*}{ Differences } & Courage & Commitment \\
\hline & Ethical behaviour & Affordability \\
\hline & Well-being & Security \\
\hline & Growth & Technology \\
\hline & Knowledge & Opportunities \\
\hline & Recognition & Selflessness \\
\hline & Talent management & Reliability \\
\hline & Emotional intelligence & - \\
\hline & Change management & - \\
\hline & Competitive edge & - \\
\hline & Employee benefits & - \\
\hline & Goals & - \\
\hline & Innovation & - \\
\hline & Job security & - \\
\hline & Learning \& development & - \\
\hline & Measurement tools & - \\
\hline & Planning & - \\
\hline & Resources & - \\
\hline & Revenue & - \\
\hline & Strategic & - \\
\hline & Self-serving & - \\
\hline
\end{tabular}




\section{Appendix 4}

TABLE 1-A4: Extract of consensus and quotes from multiple stakeholders (expert panel).

\begin{tabular}{|c|c|c|}
\hline PLA & Round 1 ranking (\%) & Extract of comments made by experts \\
\hline Courage & 84 & S1: Leaders are currently crippled by fear and not willing to take risk \\
\hline Well-being & 84 & S3: There has been a significant increase in absenteeism that is most probably related to the low morale \\
\hline Ethical behaviour & 80 & S5: The current situation of the organisation is a clear result of mismanagement, corruption; few are ethical \\
\hline Fairness & 72 & S1: In underperforming entities, this attribute is compromised, and the level of unfairness becomes exacerbated \\
\hline Strategic & 72 & S5: Does not address issues such as being open to diverse views, ambiguity, uncertainty \\
\hline Competence & 68 & S2: Competence, perhaps rather territorial competence \\
\hline Accountability & 68 & S3: That accountability is lacking for performance outputs \\
\hline Self-serving & 64 & S1: The leadership is in self-preservation mode and act in self-interest \\
\hline Selflessness & 56 & S4: Leaders expect more from their employees but are not willing to make the sacrifices themselves \\
\hline \multicolumn{3}{|l|}{ SC } \\
\hline Trust & 84 & S4: The trust in and outside of the organisation has deteriorated \\
\hline Communication & 84 & S2: Important developments in the organisation are in the media before communication is sent out via the formal channels \\
\hline Decision-making & 72 & S5: Lack of competence of leadership leads to poor decision-making \\
\hline Commitment & 72 & S5: The organisation has too many people and should cut the 'fat' \\
\hline Collaboration & 36 & S1: Most employees have a silo mentality \\
\hline \multicolumn{3}{|l|}{ OE } \\
\hline Reputation & 84 & S5: Numerous platforms where the organisation obtain feedback from, the feedback is hardly acted upon \\
\hline Employee benefits & 84 & S1: Constant pressure definitely has an impact on employee well-being \\
\hline Good governance & 80 & S2: No consequence management in place when these processes are not adhered too \\
\hline Change management & 80 & S3: Evident from the high number of new tools, processes, etc. that fail when introduced \\
\hline Competitive edge & 80 & S4: The organisation is making itself irrelevant \\
\hline Sustainability & 76 & S5: Not known for being sustainable \\
\hline Talent management & 72 & S1: The organisation has lost (resignations) many skilled employees, declining reputation \\
\hline Leadership & 48 & S3: In few instances' leadership set clear goals, provide opportunities for growth and development \\
\hline Knowledge & 40 & $\begin{array}{l}\text { S5: Knowledge should not only be restricted to technical knowledge but be inclusive of other knowledge systems (social } \\
\text { and interpersonal) }\end{array}$ \\
\hline
\end{tabular}

PLA, perceived leadership attributes; SC, social capital; OE, organisational effectiveness.

\section{Appendix 5}

TABLE 1-A5: Round 2 survey - New themes are shown.

\begin{tabular}{lll}
\hline PLAs (13) & $\begin{array}{l}\text { SC } \\
\text { (7) }\end{array}$ & $\begin{array}{l}\text { OE } \\
(\mathbf{1 4})\end{array}$ \\
\hline Self-serving & Trust & Good governance \\
Competence & Communication & Change management \\
Ethical behaviour & Decision-making & Reputation \\
Courage & Emotional intelligence & Leadership \\
Accountability & Commitment & Sustainability \\
Well-being & Collaboration & Knowledge \\
Fairness & Culture & Employee benefits \\
Selflessness & - & Talent management \\
Strategic & - & Competitive edge \\
Execution & - & SOC commitments \\
Influence & - & Shareholder expectations \\
Development & - & Productive culture \\
Empathy & - & Continuous learning \\
- & - & Positional leadership \\
\hline
\end{tabular}

PLA, perceived leadership attributes; SC, social capital; OE, organisational effectiveness; SOC, State-owned companies.

\section{Appendix 6}

TABLE 1-A6: Items that did not reach consensus by experts.

\begin{tabular}{lll}
\hline PLAs & SC & OE \\
\hline Competence & Emotional intelligence & Leadership \\
Selflessness & Collaboration & Knowledge \\
Development & - & Shareholder expectations \\
- & - & Continuous learning \\
\hline
\end{tabular}

PLA, perceived leadership attributes; SC, social capital; OE, organisational effectiveness. 


\section{Appendix 7}

PLA (Self-serving) ----> SC (Trust) <----> OE (Leadership) <----> Self-serving

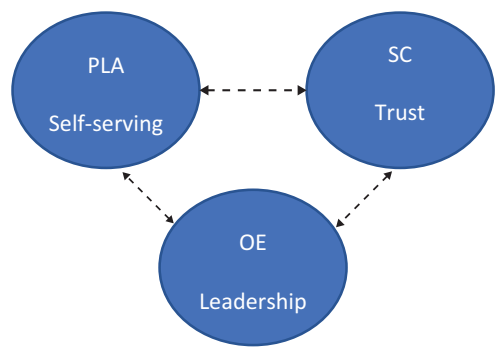

Self-serving <----> Collaboration

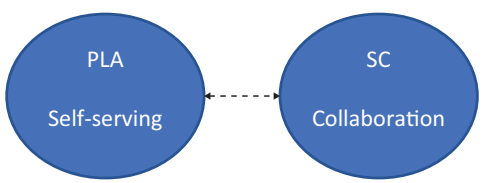

Self-serving <----> Culture

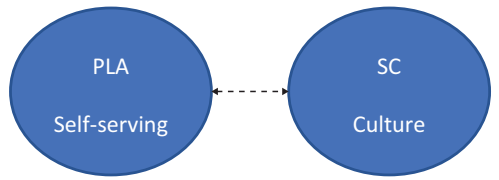

Self-serving <----> Leadership

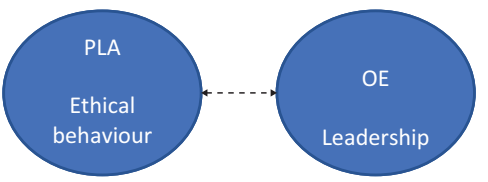

Well-being <----> Employee benefits

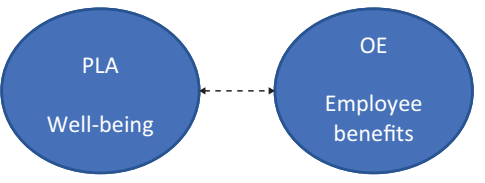

Strategic <----> Culture

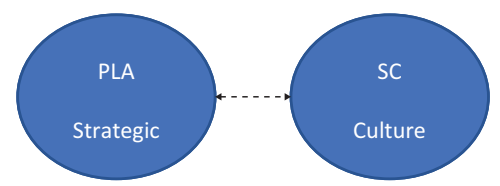

Strategic $<--->$ Collaboration

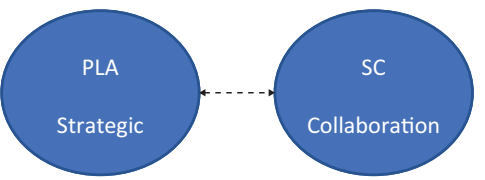

Communication <----> Reputation

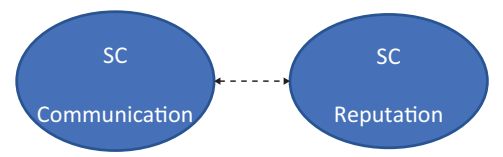

FIGURE 1-A7: The dotted line illustrates the connection between both sides. PLA, perceived leadership attributes; SC, social capital; OE, organisational effectiveness.

\section{Appendix 8}

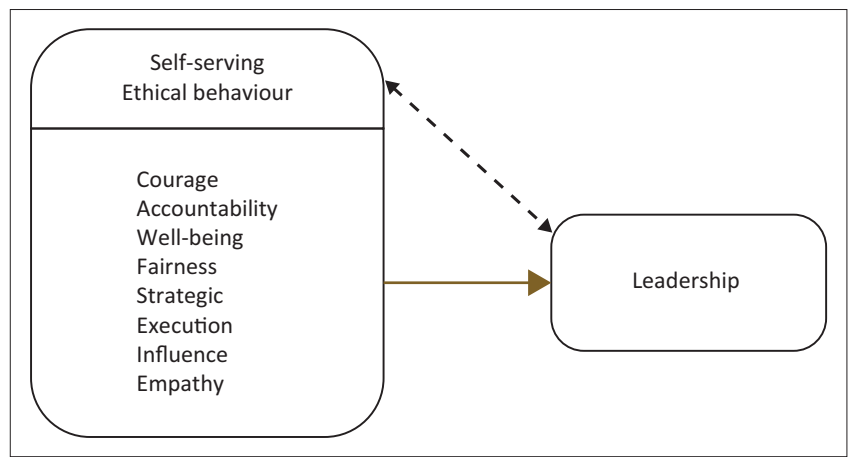

FIGURE 1-A8: All perceived leadership attributes relate to leadership.

\section{Appendix 9}

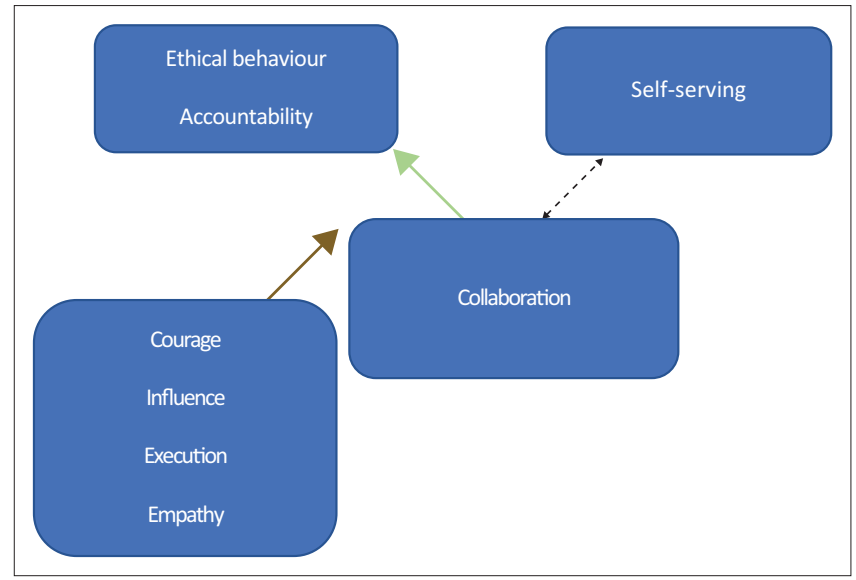

FIGURE 1-A9: Collaboration emerged as an important quality in social capital. 